\title{
Abiotic factors influencing podophyllotoxin and yatein overproduction in Leptohyptis macrostachys cultivated in vitro
}

\author{
Paloma R. Meira ${ }^{a}$, Juceni P. David ${ }^{a}$,*, Erika M. de O. Ribeiro ${ }^{a}$, José R.F. Santana ${ }^{\mathrm{b}}$, \\ Hugo N. Brandão ${ }^{\mathrm{b}}$, Lenaldo M. de Oliveira ${ }^{\mathrm{b}}$, Jorge M. David ${ }^{\mathrm{c}}$, Héctor H. Medrado ${ }^{\mathrm{c}}$, \\ José F.B. Pastore ${ }^{\mathrm{d}}$
}

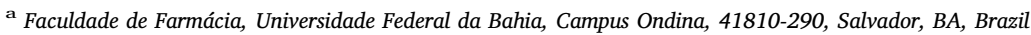

b Univerdidade Estadual de Feira de Santana, Av. Transnordestina, S/N, 44036-900, Feira de Santana, BA, Brazil

c Instituto de Química, Universidade Federal da Bahia, Campus de Ondina, 40170290, Salvador, BA, Brazil

${ }^{\mathrm{d}}$ Universidade Federal de Santa Catarina, 89520-000, Curitibanos, SC, Brazil

\section{A R T I C L E I N F O}

\section{Keywords:}

Podophyllotoxin

In vitro establishment

In vitro multiplication

Leptohyptis

\begin{abstract}
A B S T R A C T
This work describes an in vitro propagation protocol for the large-scale cultivation of Leptohyptis macrostachys (Benth.) Harley \& JFB Pastore and the influence of abiotic factors on podophyllotoxin and yatein production. The plant was established from seeds collected in Chapada Diamantina, BA, Brazil and submitted to different growth mediums and physical conditions. The podophyllotoxin and yatein contents were quantified by HPLC/DAD and with pure standards and these two lignans were present in all experiments. The lignan quantities were evaluated using the Sisvar Program, compared by Tukey's test and hierarchical cluster analysis and principal component analysis. In all experiments, podophyllotoxin and yatein were detected at different concentrations. The best protocol cultivar of $L$. macrostachys was established from seeds in MS $1 / 2$ medium supplemented with $1.5 \%$ sucrose and $11.55 \mu \mathrm{M}$ of gibberellic acid $\mathrm{A} 3\left(\mathrm{GA}_{3}\right)$ at $30^{\circ} \mathrm{C}$, which yielded the highest concentration of podophyllotoxin $\left(5.831 \mathrm{mg} \mathrm{g}^{-1}\right)$. These results are important findings for the production of podophyllotoxin from the tissue culture.
\end{abstract}

\section{Introduction}

Podophyllotoxin (Fig. 1) is one the most active cytotoxic natural products and is used as a starting compound for the synthesis of the anticancer drugs etoposide and teniposide (Brandão et al., 2010). Currently, the commercial sources of podophyllotoxin are the rhizomes and roots of Podophyllum emodi Wall., Berberidaceae. The search for new and renewable sources of podophyllotoxin is important because Podophyllum spp is endangered due to the exhaustive extraction of this compound (Medrado et al., 2015). The presence of aryltetralin lignans, including podophyllotoxin, as minor compounds in Eriope and Hyptis species (Fig. 1) has previously been reported (Novelo et al., 1993; Santos et al., 2011). Lamiaceae is comprised of 220 genera with approximately 4000 species occurring all over the world. Leptohyptis macrostachys (Benth.) Harley \& JFB Pastore (Harley and Pastore, 2012) is a recurrent Lamiaceae species previously classified in the genus Hyptis. This species occurs in the Central and South America. In Brazil, it habitats the northeastern semi-arid region and is a species found in the semi-arid region of Brazil and it is popularly known as "alfavaca- brava" and "hortelã-do-mato". In folk medicine, tea and syrup of its aerial parts are used orally to relief symptoms in asthma, cough and bronchitis used by the locals (Agra et al., 2008). Other closer species of this genus, such as $H$. brevipes, occurs all over the word and it also is used in folk medicine for the treatment of asthma, besides malaria, cancer and pest-repelling (Suárez-Ortiz et al., 2017). Previously chemical studies concerning Hyptis spp. describe the presence of aryltetralins lignans in different plant parts (Raffauf et al., 1987) and a set 6heptyl-5,6-dihydro-2H-2-one derivatives (Suárez-Ortiz et al., 2013).

An understanding of the biotechnological processes of cell, tissue and organ culture or intact plant culture for the production of bioactive compounds are very important to overcome problems from cultivation, such as seasonality, environmental variation, geographical location, pest attack and political instability (Hussain et al., 2012). Tissue culture can be used to induce qualitative and quantitative changes in the production of metabolites by altering nutrients and/or regulators in the conditions of in vitro growth. Thus, the use of biotechnological tools, such as tissue culture, can facilitate the homogenous and well-defined production of secondary metabolites from plant sources (Affonso et al.,

\footnotetext{
* Corresponding author.

E-mail address: juceni@ufba.br (J.P. David).
} 
<smiles>[R3]C1c2c(cc(C(C)=O)c(O)c2OC)[C@@H](c2cc(OC)c(O)c(OC(C)(C)C)c2)[C@@H]2C(=O)OCC12</smiles>

$1 \mathrm{R}_{1}=\mathrm{H}, \mathrm{R}_{2}=\mathrm{OH}, \mathrm{R}_{3}=\mathrm{CH}_{3}$

$2 \mathrm{R}_{1}=\mathrm{OH}, \mathrm{R}_{2}=\mathrm{H}, \mathrm{R}_{3}=\mathrm{CH}_{3}$

$3 \mathrm{R}_{1}=\mathrm{OH}, \mathrm{R}_{2}=\mathrm{H}, \mathrm{R}_{3}=\mathrm{H}$<smiles>COc1cc(CC2C(=O)OCC2Cc2ccc3c(c2)OCO3)cc(OC)c1OC</smiles>

4

Fig. 1. Aryltetralins lignans present in Lamiaceae species.

2009). The yield of such production has been assessed by analytical methods such as HPLC/DAD, which is a broadly used technique to estimate the concentration of in vitro and in vivo bioactive compounds (Vijayan et al., 2015).

This work describes the influence of abiotic factors in the development of the in vitro culture of $L$. macrostachys and on the production and concentration of podophyllotoxin and yatein (4, Fig. 1), its direct biosynthetic precursor.

\section{Materials and methods}

\subsection{Plant material}

Leptohyptis macrostachys seeds were collected from the surroundings of Mucugê, a city above sea level over $1003 \mathrm{~m}$ in the region of Chapada Diamantina $\left(13^{\circ} 0^{\prime} 22^{\prime \prime S} 11^{\circ} 22^{\prime} 34^{\prime \prime} \mathrm{W}\right)$, Bahia, Brazil. A voucher (\#127644) is deposited in the Herbarium of Universidade Federal da Bahia. The seeds were subjected to surface disinfestation by the immersion in $70 \%$ alcohol ( $1 \mathrm{~min}$ ), followed by sodium hypochlorite ( $1.0 \%$ active chlorine) with one drop of neutral detergent $(10 \mathrm{~min})$, and finished with three washes with sterile distilled water to remove any trace of chlorine.

\subsection{In vitro germination experiments of Leptohyptis macrostachys}

Seeds were inoculated in glass tubes $(20 \mathrm{~cm} \times 1.5 \mathrm{~cm})$ containing approximately $10 \mathrm{~mL}$ of MS culture medium according to Murashige and Skoog (1962), with variations in the concentration of basal salts and various supplementations. The culture media used had the following salt concentrations: 1.) MS with the total concentration of salts (complete MS); 2.) MS with the salt concentration reduced by half $(1 / 2$ MS); and 3.) MS medium with no added salt (agar). All media containing sucrose (3\%) and solidified with agar (0.7\%). Seeds were sown in MS medium, $1 / 2$ MS medium with no supplementation, and $1 / 2$ MS medium containing either $1.5 \%$ sucrose or $3 \%$ sucrose, all solidified with agar $(0.7 \%)$. To evaluate the effect of gibberellic acid (GA3), the seeds were inoculated in $1 / 2$ MS medium solidified with $0.7 \%$ agar, supplemented with $3 \%$ sucrose and either $2.88 \mu \mathrm{M}, 5.77 \mu \mathrm{M}$ or $11.55 \mu \mathrm{M}$ gibberellic acid. The $\mathrm{pH}$ of the culture medium was adjusted to $5.7 \pm 0.1$ before autoclaving (for $15 \mathrm{~min}$ at $121^{\circ} \mathrm{C}$ and $15 \mathrm{psi}$ ) all media. The cultures were maintained at $25^{\circ} \mathrm{C}$ for 30 days in a growth chamber with a relative humidity of $60 \%$ and a photosynthetic radiation activity of $30 \mu \mathrm{mol} \mathrm{m} \mathrm{m}^{-1}$.

\subsection{In vitro multiplication experiments with L. macrostachys}

The plants germinated in vitro by the different methods were used at 30 days of age as the source of explants. Explants (node region) of approximately $0.5 \mathrm{~cm}$ in length were individually inserted into test tubes with approximately $10 \mathrm{~mL}$ of MS or $1 / 2 \mathrm{MS}$ medium, both supplemented with $3 \%(\mathrm{w} / \mathrm{v})$ or $1.5 \%(\mathrm{w} / \mathrm{v})$ sucrose and solidified with agar $(0.7 \%)$. Cultures were maintained in a proper growth chamber at $25{ }^{\circ} \mathrm{C}$ for 30 days with $60 \%$ of relative humidity and photosynthetic active radiation of $30 \mu \mathrm{mol} \mathrm{m} \mathrm{s}^{-1}$. In addition, the production of podophyllotoxin and yatein contents were carried out in all experiments.

\subsection{Effect evaluation of 6-benzylaminopurine (BAP) and naphthalene acetic acid (NAA)}

The explants were inserted on $1 / 2$ MS medium containing $3 \%$ sucrose and BAP $(0,4.44$, or $8.88 \mu \mathrm{M})$ combined with NAA $(0,5.37$, or $10.74 \mu \mathrm{M})$ and solidified with agar $(0.7 \%)$. The cultures were maintained at $25 \pm 3{ }^{\circ} \mathrm{C}$ for 30 days in a growth chamber with a relative humidity of $60 \%$ and photosynthetic active radiation of $30 \mu \mathrm{mol} \mathrm{m} \mathrm{s}^{-} \mu \mathrm{mol} \mathrm{m} \mathrm{s}^{-1}$.

\subsection{Effect of temperature, tube closing evaluation and photoperiod}

The explants were inoculated on MS culture medium with half the total concentration of salt, containing $3 \%$ sucrose and solidified with agar $(0.7 \%)$. The cultures were maintained at $25{ }^{\circ} \mathrm{C}$ for 30 days in a growth chamber with a relative humidity of $60 \%$ and photosynthetic active radiation of $30 \mu \mathrm{mol} \mathrm{m} \mathrm{s}^{-1}$ (control) or at $30{ }^{\circ} \mathrm{C}$ for 30 days in a growth chamber with a relative humidity of $60 \%$ and photosynthetic active radiation of $30 \mu \mathrm{mol} \mathrm{m}{ }^{2} \mathrm{~s}^{-} \mu \mathrm{mol} \mathrm{m} \mathrm{s}^{-1}$. Two types of test tube closures were studied: with PVC (not allowing gas exchange) and with a plastic cover (allowing gas exchange). Cultures were maintained at $25{ }^{\circ} \mathrm{C}$ for 30 days in the same growth chamber conditions. It was also evaluated the photoperiod of $16 \mathrm{~h}$ of light for the control group and $8 \mathrm{~h}$ of light for the test group in the inoculated explants.

\subsection{HPLC analysis of lignans}

The chromatographic analyses were carried out using a Shimadzu ${ }^{\star}$ (Corp., Kyoto, Japan) HPLC equipment model 2010 with an autoinjector (SIL-10AD model), solvent pump (SCL-10AVP model) and UV-vis detector (SPD-M10A,). The chromatographic separation was performed employing a LiChroCART Purospher Star ${ }^{\circ}$ RP18-e column (50 $\mathrm{mm} \times 4 \mathrm{~mm}$ i.d.) $(3 \mu \mathrm{m})$ combined with a pre-column $(3 \mu \mathrm{m})$ (LiChroCART 4-4 LiChrospher 100 RP18, Merck Darmastad, Germany). Podophyllotoxin standard were purchased (Sigma-Aldrich, USA) and yatein was previously isolated from Eriope blanchetii. The yatein purity was determined by HPLC and NMR (Santos et al., 2011).

The plants grown in vitro were dried in a hot air circulation oven at $40{ }^{\circ} \mathrm{C}$ for $48 \mathrm{~h}$. The extraction was briefly performed by adding $15 \mathrm{~mL}$ of ethanol to every $2 \mathrm{~g}$ of dried plant material, which was then mixed and maintained at $40{ }^{\circ} \mathrm{C}$ for $2 \mathrm{~h}$, under agitation. The ethanolic extracts were filtered, and the solutions were completely dried in a fume hood with a heat pistol. The dried extract was then resuspended and partitioned with water and ethyl acetate (1:1). The resulting ethyl acetate phase was divided in half, and the solvent was evaporated. The semipurified extract was then dissolved in $10 \mathrm{~mL}$ of aqueous solution of acetonitrile $\left(8: 2 \mathrm{H}_{2} \mathrm{O}: \mathrm{ACN}\right)$ and pre-concentrated using a Sep-Pak C18 cartridge. The compounds absorbed in the cartridge were eluted with $10 \mathrm{~mL}$ of acetonitrile in a measured vial and taken to dryness. The material was then redissolved in methanol, filtered through a $0.22-\mu \mathrm{m}$ membrane (Supelco, Pennsylvania, USA) and injected onto the HPLC. All procedures were performed in triplicate. Methanol, water, 
acetonitrile and acetic acid (all HPLC grade) were employed for the HPLC mobile phase, and two systems were used in the gradient elution: solvent A (MeOH: $\left.\mathrm{H}_{2} \mathrm{O}: \mathrm{AcOH} 14: 85: 1\right)$ and solvent B (ACN). Initially, a mixture of A and B (8:2) was eluted for $8 \mathrm{~min}$, progressively decreasing to $7.8: 2.2$ and $7: 3$ at $12 \mathrm{~min}$ and $5.5: 4.5$ by $18 \mathrm{~min}$. The full analysis lasted $22 \mathrm{~min}$ with a flow rate of $0.8 \mathrm{~mL} \mathrm{~min}^{-1}$ and an injection volume of $2 \mu \mathrm{L}$ at ambient temperature. The read range of the array detector diode was established in 210 to $400 \mathrm{~nm}$, and the chromatographic acquisition was set at $290 \mathrm{~nm}$. The identification of lignans was obtained by a comparison of retention times of standards and samples, as well as the obtained mass and ultraviolet spectra.

\subsection{Statistical and multivariate data analyzes}

To analyze the data obtained in the germination experiments and the in vitro multiplication of Leptohyptis macrostachys, the SISVAR program (Ferreira, 2011) was used and tested at 1\% probability. The means were compared by Tukey's test.

The determinated content of lignans $\left(\mathrm{mg} \mathrm{g}^{-1}\right.$ dried material) are multivariate and we therefore used the Principal Component Analysis (PCA) and Hierarchical Cluster Analysis (HCA), which are multivariate chemometric methods, to identify similarities and trends in groups of compounds induced by different culture conditions (Table 1). The software Origin ${ }^{\circledR} 2017$ was used for the PCA and HCA calculations.

\section{Results and discussion}

The results were analyzed based on the parameters employed in the establishment of L. macrostachys in vitro cultivation. From the HPLC/ DAD qualitative and quantitative informations about podophyllotoxin and yatein were possible to evaluated all results employing PCA and HCA chemometrics analysis. Thus, the best parameters employed to establish a method of in vitro germination for L. macrostachys were observed with seeds germinated on MS medium with half the concentration of salt ( $1 / 2$ MS) supplemented with $1.5 \%$ sucrose, $11.55 \mu \mathrm{mol} \mathrm{L}^{-1} \mathrm{GA}_{3}$ solidified with $0.7 \%$ agar and maintained in a growth chamber with a photoperiod of $16 \mathrm{~h}$ at $25^{\circ} \mathrm{C}$. The complete regeneration of the plant was best achieved in two subcultures: the first favoring shoot growth and the second strengthening roots.

The identification and quantification of podophyllotoxin and yatein employing HPLC/DAD/MS allowed us to obtain chromatograms and UV and MS spectra, which indicated the presence of both lignans in all cultivation conditions. The chromatographic method quickly and adequately showed retention times recorded for podophyllotoxin between 12.2 to $12.5 \mathrm{~min}$ and 14.2 to $15.4 \mathrm{~min}$ for yatein. A comparison with external standards and the calibration curves allowed us to obtain the

Table 1

Quantification ( $\mathrm{mg} \mathrm{g}^{-1}$ of dry plant) of the production of podophyllotoxin and yatein in different culture conditions.

\begin{tabular}{lll}
\hline Culture & podophyllotoxin & yatein \\
\hline Control in vitro & $0.4015 \pm 0.0053$ & $7.1839 \pm 0.0548$ \\
$0 \mu \mathrm{M}$ BAP $+5.37 \mu \mathrm{M}$ ANA & $0.2926 \pm 0.0120$ & $1.8553 \pm 0.0551$ \\
$0 \mu \mathrm{M}$ BAP $+10.74 \mu \mathrm{M}$ ANA & $0.4670 \pm 0.0089$ & $1.0705 \pm 0.0094$ \\
$4.44 \mu \mathrm{M}$ BAP $+0 \mu \mathrm{M}$ ANA & $0.8431 \pm 0.0104$ & $6.6848 \pm 0.0828$ \\
$4.44 \mu \mathrm{M}$ BAP $+5.37 \mu \mathrm{M}$ ANA & $2.243 \pm 0.0112$ & $4.2934 \pm 0.0021$ \\
$4.44 \mu \mathrm{M}$ BAP $+10.74 \mu \mathrm{M}$ ANA & $1.1091 \pm 0.0016$ & $2.0343 \pm 0.2745$ \\
$8.88 \mu \mathrm{M}$ BAP $+0 \mu \mathrm{M}$ ANA & $0.6678 \pm 0.0081$ & $4.1824 \pm 0.0485$ \\
$8.88 \mu \mathrm{M}$ BAP $+5.37 \mu \mathrm{M}$ ANA & $4.0871 \pm 0.0509$ & $6.4908 \pm 3.7483$ \\
$8.88 \mu \mathrm{M}$ BAP $+10.74 \mu \mathrm{M}$ ANA & $1.0787 \pm 0.0065$ & $3.5098 \pm 0.2022$ \\
photoperiod & $0.0944 \pm 0.0021$ & $15.0663 \pm 0.3902$ \\
Temperature & $0.8372 \pm 0.1368$ & $24.2097 \pm 0.0994$ \\
Gas changes & $0.1777 \pm 0.0242$ & $0.6151 \pm 0.0321$ \\
$1 / 2 \mathrm{MS}, 15 \mathrm{~g}$ sucrose & $5.8309 \pm 0.1255$ & $8.3176 \pm 0.1213$ \\
$1 / 2 \mathrm{MS}, 30 \mathrm{~g}$ sucrose & $0.6791 \pm 0.4193$ & $22.4590 \pm 0.0341$ \\
MS INT, $15 \mathrm{~g}$ sucrose & $2.8706 \pm 0.0346$ & $1.8750 \pm 0.0163$ \\
MS INT, $30 \mathrm{~g}$ sucrose & $1.5442 \pm 0.3177$ & $3.2579 \pm 0.6721$ \\
\hline
\end{tabular}

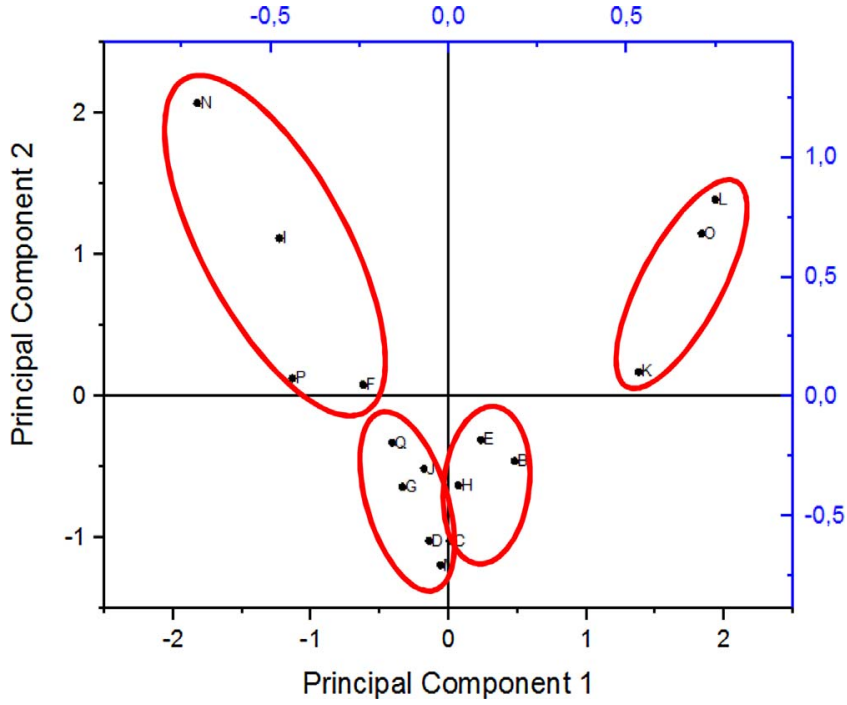

Fig. 2. PC1 versus PC2 das diferentes condições de cultivo de Leptohyptis macrostachys, baseadas na quantificação de podofilotoxina e yateína. Onde: $\mathrm{B}=$ Control in vitro, $\mathrm{C}=0 \mu \mathrm{M}$ BAP $+5.37 \mu \mathrm{M}$ ANA, $\mathrm{D}=0 \mu \mathrm{M}$ BAP $+10.74 \mu \mathrm{M}$ ANA, $\mathrm{E}=4.44 \mu \mathrm{M}$ BAP $+0 \mu \mathrm{M}$ ANA, $\mathrm{F}=4.44 \mu \mathrm{M}$ BAP $+5.37 \mu \mathrm{M}$ ANA, $\mathrm{G}=4.44 \mu \mathrm{M}$ BAP $+10.74 \mu \mathrm{M}$ ANA, $\mathrm{H}=8.88 \mu \mathrm{M}$ BAP $+0 \mu \mathrm{M}$ ANA, $\mathrm{I}=8.88 \mu \mathrm{M}$ BAP $+5.37 \mu \mathrm{M}$ ANA, $J=8.88 \mu \mathrm{M}$ BAP $+10.74 \mu \mathrm{M}$ ANA, $\mathrm{K}=$ photoperiod, $\mathrm{L}=$ Temperature, $\mathrm{M}=$ Gas changes, $\mathrm{N}=1 / 2 \mathrm{MS}$, $15 \mathrm{~g}$ sucrose, $\mathrm{O}=1 / 2 \mathrm{MS}, 30 \mathrm{~g}$ sucrose, $\mathrm{P}=$ MS INT, $15 \mathrm{~g}$ sucrose e $\mathrm{Q}=$ MS INT, $30 \mathrm{~g}$ sucrose.

concentration of these two compounds in the produced matrixes. All analyses were carried out in triplicate, and the results are expressed in Table 1.

The obtained data were evaluated by chemometric methods of exploratory analysis (PCA and HCA). The multivariate analyzes of PCA applied to the contents of podophyllotoxin and yatein from the different culture conditions of $L$. macrostachys are summarized in Fig. 2. Two principal components (PC) are responsible for $100 \%$ data variance (53.93\% for PC1 and $46.07 \%$ for PC2). From these two components was possible to separate L. macrostachys plantets in four similar groups accordance with the culture conditions. PC1 showed a good separation between $\mathrm{K}, \mathrm{L}$ and $\mathrm{O}$ (positive scores) from D, F, G, I, J, M, N, P and Q culture conditions (PC1 negative scores). However, in PCA the separation of cultures $\mathrm{K}, \mathrm{L}$ and $\mathrm{O}$ from the cultures $\mathrm{B}, \mathrm{C}, \mathrm{E}$ and $\mathrm{H}$ were just confirmed by the positive and negative scores of PC2. In the same plot the PCA permitted to identify the culture conditions ( $\mathrm{C}, \mathrm{H}$ and $\mathrm{E}$ ) which presented similarity with the in vitro control experiment. These conditions showed positive and negative scores in PC1 and PC2, respectively.

The results obtained by HCA are in agreement with the PCA results with regard to the resemblance in treatments. The HCA (Fig. 3) permitted to group the results in two distinct regions in the Dendogram and to classify the sixteen cultures of $L$. macrostachys. The culture conditions B, E, I, N, C, G, D, M, P, F, H, J and Q (black) were considerated class 1 and the conditions $\mathrm{K}, \mathrm{L}$ and $\mathrm{O}$ (red) were named Class 2. This two class showed no similarities. Thus, the experiments K, L and $\mathrm{O}$ are characterized culture conditions that are differentiated in terms of podophyllotoxin and yatein productions. Comparing the culture conditions of class $2(\mathrm{~K}, \mathrm{~L}$ and $\mathrm{O})$, the experiment $\mathrm{K}$ clearly is different from the other two conditions, especially in yatein production.

The production of podophyllotoxin was influenced both by the concentration of sucrose and salt in the culture medium. The yield of this compound was greater when $1 / 2$ MS supplemented with $1.5 \%$ sucrose was employed. However, the production of yatein was influenced by only the concentration of basal salt in the cultivation medium. The greatest yield of yatein was observed in the medium containing half the concentration of salt (Table 2).

The podophyllotoxin content was on average higher for the ratio of plant growth regulators composed of $8.88 \mu \mathrm{M}$ of BAP and $5.37 \mu \mathrm{M}$ of 


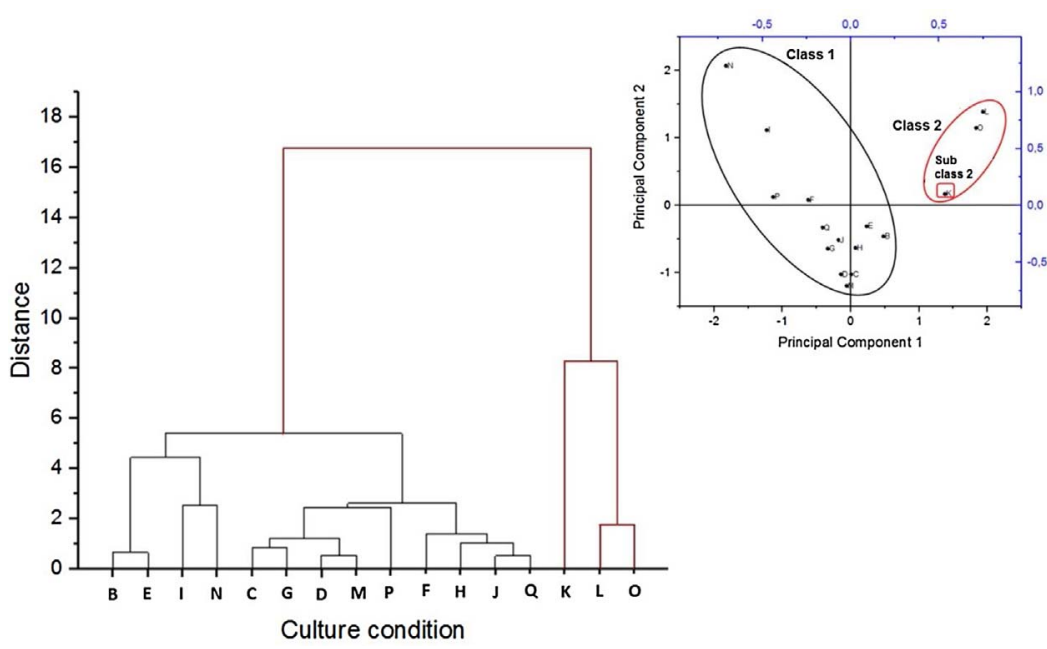

Fig. 3. Dendograma correspondente à classificação de diferentes condições de cultura de Leptohyptis macrostachys, baseadas na quantificação de podofilotoxina e yateína. Onde: $\mathrm{B}=$ Control in vitro, $\mathrm{C}=0 \mu \mathrm{M} \quad \mathrm{BAP}+5.37 \mu \mathrm{M} \quad$ ANA,$\quad \mathrm{D}=0 \mu \mathrm{M} \quad \mathrm{BAP}+10.74 \mu \mathrm{M} \quad$ ANA, $\mathrm{E}=4.44 \mu \mathrm{M} \quad \mathrm{BAP}+0 \mu \mathrm{M} \quad \mathrm{ANA}, \quad \mathrm{F}=4.44 \mu \mathrm{M} \quad \mathrm{BAP}+5.37 \mu \mathrm{M} \quad$ ANA, $\mathrm{G}=4.44 \mu \mathrm{M}$ BAP $+10.74 \mu \mathrm{M}$ ANA, $\mathrm{H}=8.88 \mu \mathrm{M}$ BAP $+0 \mu \mathrm{M}$ ANA, $\mathrm{I}=8.88 \mu \mathrm{M}$ BAP $+5.37 \mu \mathrm{M}$ ANA, $J=8.88 \mu \mathrm{M}$ BAP $+10.74 \mu \mathrm{M}$ ANA, $\mathrm{K}=$ photoperiod, $\mathrm{L}=$ Temperature, $\mathrm{M}=$ Gas changes, $\mathrm{N}=1 / 2 \mathrm{MS}, 15 \mathrm{~g}$ sucrose, $\mathrm{O}=1 / 2 \mathrm{MS}, 30 \mathrm{~g}$ sucrose, $\mathrm{P}=$ MS INT, $15 \mathrm{~g}$ sucrose e $\mathrm{Q}=\mathrm{MS}$ INT, $30 \mathrm{~g}$ sucrose.

Table 2

Average values of podophyllotoxin and yatein in Leptohyptis macrostachys plants as a function of the salt and sucrose concentrations in the culture medium.

\begin{tabular}{llll}
\hline Concentration of salts & Yatein & \multicolumn{2}{l}{ Podophyllotoxin } \\
\cline { 3 - 4 } & & $1.5 \%$ sucrose & $3.0 \%$ sucrose \\
\hline MS $1 / 2$ & 3.5449 & 5.8309 & 0.6791 \\
MS complete & 1.9026 & 2.8705 & 1.5442 \\
\hline
\end{tabular}

Values showed significant differ at $5 \%$ probability by Tukey's test.

NAA. The yatein appears to have been inhibited by the presence of NAA, and its average was higher in the absence of this auxin (Table 3).

In a summary of the analysis of variance on the effect of temperature, it was evident that both podophyllotoxin and yatein showed statistically significant differences (Table 1). The comparison of the means shows that yatein and podophyllotoxin, on average, were produced in greater numbers when cultured at $30^{\circ} \mathrm{C}$ (Table 4).

A comparison of means shows that the production of podophyllotoxin and yatein was favored under a PVC film sealant, but also in a greater volume of medium when a plastic cover was used (Table 5).

The comparison of averages shows that podophyllotoxin on average was better produced in a photoperiod of $16 \mathrm{~h}$, whereas yatein was better produced in a photoperiod of $8 \mathrm{~h}$ (Table 4). Thus, podophyllotoxin production can be improved in vitro if maintained on MS medium with half the concentration of salt, supplemented with $1.5 \%$ sucrose, sealed with PVC film, and kept in a growth room at $30{ }^{\circ} \mathrm{C}$ with photoperiod of $16 \mathrm{~h}$. With the exception of the concentration of salt in the culture medium and the concentration of sucrose, these same conditions favor the number of leaves and/or buds.

Wild Leptohyptis macrostachys specimens collected in the region of Diamantina Chapada (Bahia, Brazil), when subjected to the same methods of extraction and quantification, showed podophyllotoxin on leaves with a yield of $0.089 \mathrm{mg} \mathrm{g}^{-1}$ dried plant material (Brandão et al.,
Table 4

Average values of podophyllotoxin and yatein in Leptohyptis macrostachys plants as a function of temperature, type of cover and photoperiod.

\begin{tabular}{|c|c|c|c|c|c|c|}
\hline & \multicolumn{2}{|c|}{ Temperature $\left({ }^{\circ} \mathrm{C}\right)$} & \multicolumn{2}{|c|}{ Types of Closing } & \multicolumn{2}{|c|}{ Photoperiod (h) } \\
\hline & 25 & 30 & PVC film & $\begin{array}{l}\text { plastic } \\
\text { cover }\end{array}$ & 16 & 8 \\
\hline podophyllotoxin & 0.4015 & 0.8372 & 0.4015 & 0.1777 & 0.4015 & 0.0944 \\
\hline yatein & 7.1839 & 24.2097 & 7.1839 & 0.6151 & 7.1839 & 15.0663 \\
\hline
\end{tabular}

Analyzing each factor separately (Temperature, Types of closing and Photoperiod), values differ by $5 \%$ of probability by the Tukey test.

2017). Cultivated in vitro on MS medium contained 1.5\% sucrose, Leptohyptis macrostachys produced $5.83 \mathrm{mg} \mathrm{g}^{-1}$ (Fig. 4).

However, podophyllotoxin production is very low compared to yatein production (Figs. 5 and 6). Therefore, more studies are needed to move the turnover of the biosynthesis reaction to enhance the formation of podophyllotoxin.

\section{Conclusions}

The concentration of podophyllotoxin can be improved in the in vitro culture of Leptohyptis macrostachys if maintained on MS medium with half the concentration of salt, contained $1.5 \%$ sucrose, sealed with PVC film and kept in a growth chamber at $30{ }^{\circ} \mathrm{C}$ with a photoperiod $16 \mathrm{~h}$. Also, in this case, subculture may further increase yields, as the concentration of yatein, the precursor of podophyllotoxin, is favored under conditions (photoperiod and temperature, for example) that are averse to podophyllotoxin production. Comparing with previous studies dealing with new sources of podophyllotoxin from collected plant and/ or in vitro induced plant the present good results showing the production of this compound, especially with cultures employing $8.88 \mu \mathrm{M}$ BAP $+5.37 \mu \mathrm{M}$ ANA. From Juniperus scopulorum the highest level of podophyllotoxin characterized was $486.7 \mathrm{mg} / 100 \mathrm{~g}$ DW (Och et al.,

Table 3

Average values of podophyllotoxin and yatein in Leptohyptis macrostachys plants for different concentrations of BAP and NAA

\begin{tabular}{|c|c|c|c|c|c|c|}
\hline \multirow[t]{2}{*}{ NAA $(\mu \mathrm{M})$} & \multicolumn{3}{|c|}{ Podophyllotoxin BAP $(\mu \mathrm{M})$} & \multicolumn{3}{|c|}{ Yatein BAP $(\mu \mathrm{M})$} \\
\hline & 0.00 & 4.44 & 8.88 & 0.00 & 4.44 & 8.88 \\
\hline 0.00 & $0.4015 \mathrm{Ab}$ & $0.8431 \mathrm{Ca}$ & $0.6678 \mathrm{Ba}$ & $7.1838 \mathrm{Ab}$ & $6.6848 \mathrm{Ad}$ & $4.1824 \mathrm{Ba}$ \\
\hline 5.37 & $0.2926 \mathrm{Aa}$ & $2.2430 \mathrm{Bc}$ & $4.0871 \mathrm{Cc}$ & $1.8553 \mathrm{Aa}$ & $4.2934 \mathrm{Ae}$ & $4.3272 \mathrm{Aa}$ \\
\hline 10.74 & $0.4670 \mathrm{Ac}$ & $1.1091 \mathrm{Bb}$ & $1.0787 \mathrm{Bb}$ & $1.0705 \mathrm{Aa}$ & $2.0343 \mathrm{~A}$ & $3.5098 \mathrm{Aa}$ \\
\hline
\end{tabular}

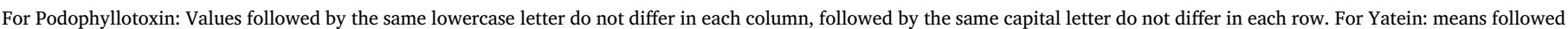
by the same lower case letter in each column do not differ at $5 \%$ probability by Tukey's test. Followed by the same capital letter do not differ in each row. 

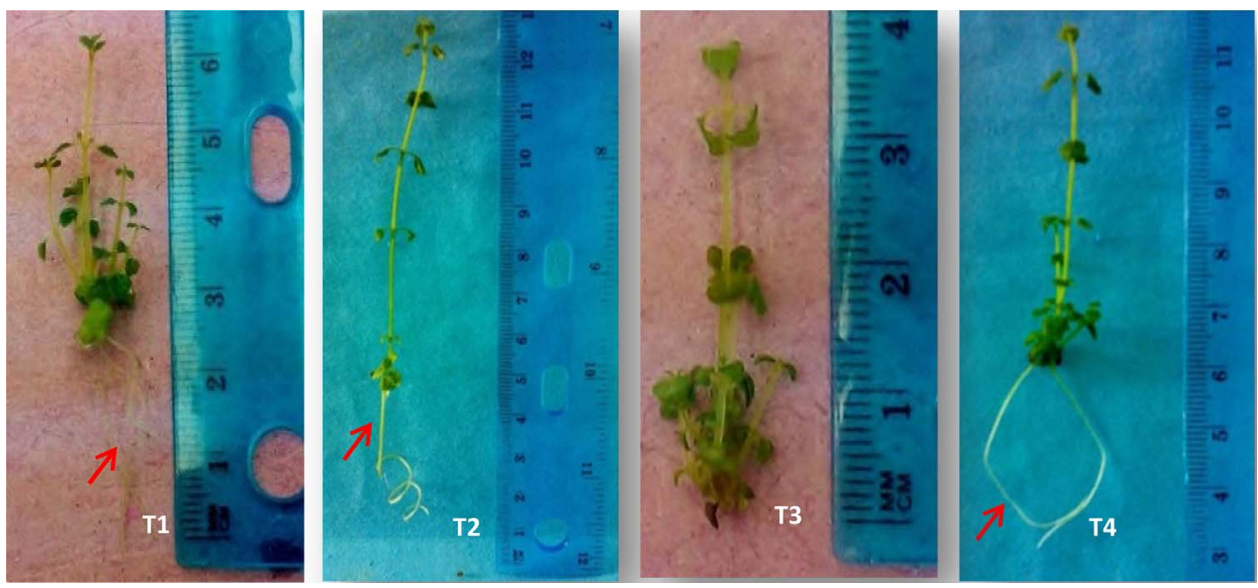

\section{Podophyllotoxin}

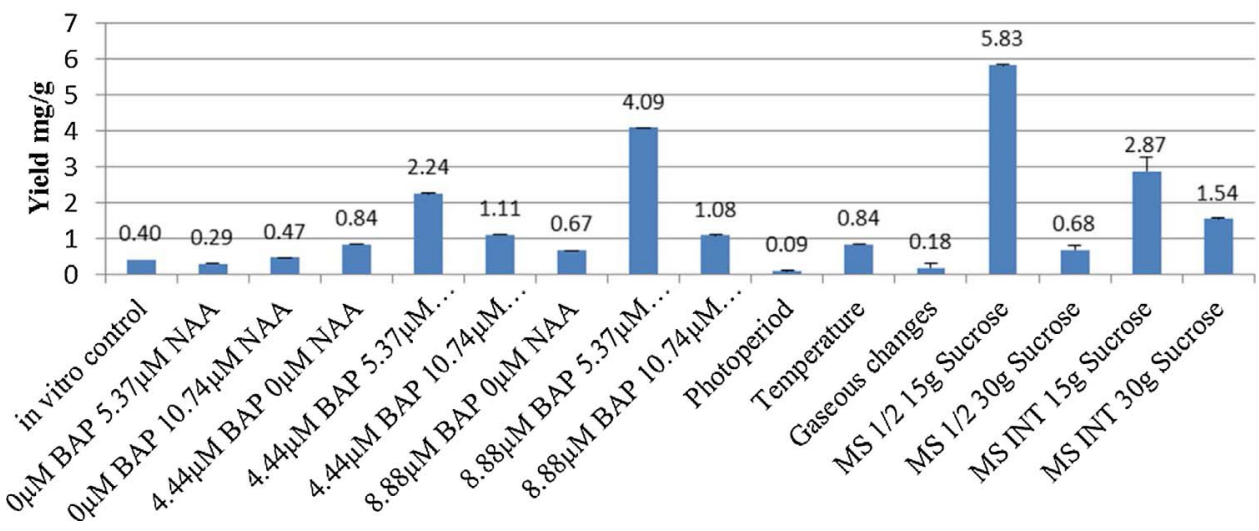

Fig. 4. In vitro establishment of Leptohyptis macrostachys $(\mathrm{T} 1=1 / 2 \mathrm{MS}$ and $1.5 \%$ sucrose; $\mathrm{T} 2=1 / 2 \mathrm{MS}$ $3.0 \%$ sucrose; $\mathrm{T} 3=1 \mathrm{MS} 1.5 \%$ sucrose; $\mathrm{T} 4=1 \mathrm{MS}$ $1.5 \%$ sucrose). Roots are indicated by the red arrows. (For interpretation of the references to colour in this figure legend, the reader is referred to the web version of this article.)

Fig. 5. Comparison of yield ( $\mathrm{mg} \mathrm{g}^{-1}$ dried plant material) podophyllotoxin in Leptohyptis macrostachys plants cultured in vitro.

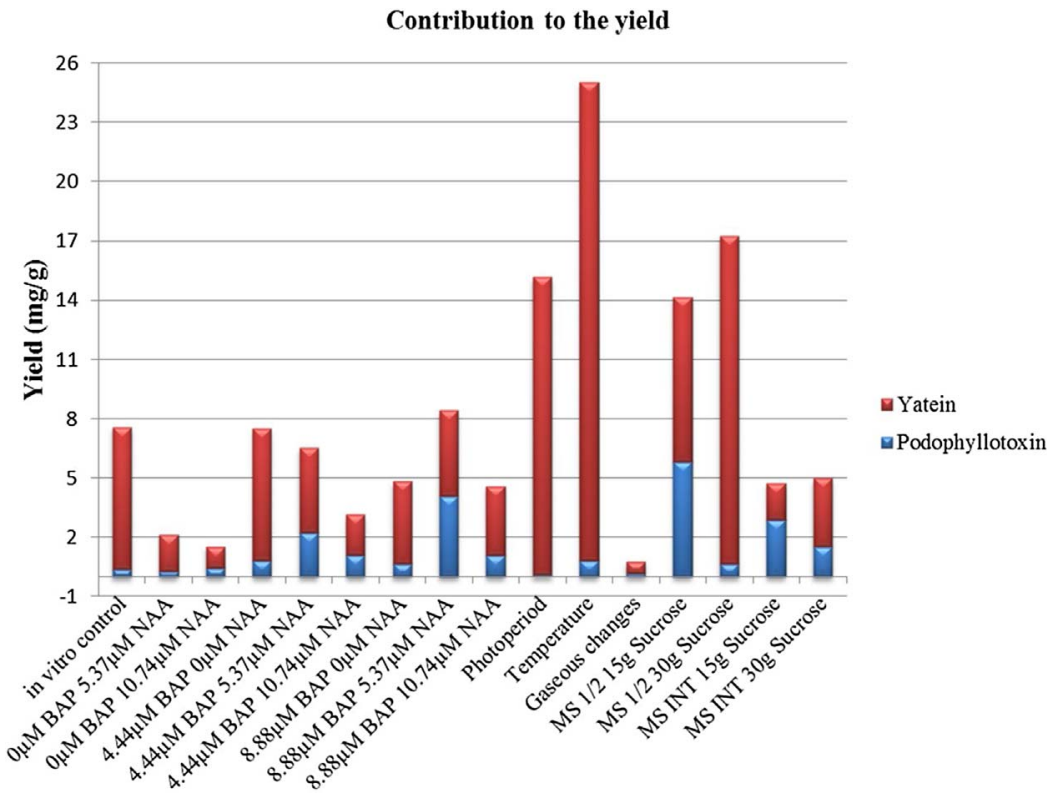

Fig. 6. Comparison of mean considering the yield ( $\mathrm{mg} \mathrm{g}^{-1}$ of dry plant) of podophyllotoxin $\times$ yatein in Leptohyptis macrostachys plants cultivated in vitro.

2015). And, previous studies with in vitro-induced roots and roots regenerated from calli of Podophyllum hexandrum Royle produced $11.625 \%$ and $10.5 \%$ enhanced quantities of podophyllotoxin of dry weight of the cultures while in plant drug it was $9.3 \%$ of the dry weight of plant root rhizome (Sagar and Zafar, 2005). Therefore, this work demonstrated that species of Lamiaceae could potentially serve as an alternative source of podophyllotoxin or its biossinthetic precursors by in vitro cultures.

\section{Acknowledgments}

The authors thank Brazilian Conselho Nacional de Desenvolvimento Científico e Tecnológico (CNPq) and Fundação de Amparo a Pesquisa da Bahia (FAPESB) for the grants and scholarship. 


\section{References}

Affonso, V.R., Bizzo, H.R., Lage, C.L.S., Sato, E., 2009. Influence of growth regulators on biomass production and volatile profile of in vitro plantlets of Thymus vulgaris L. J. Agric. Food Chem. 57, 6392-6395. http://dx.doi.org/10.1021/jf900816c.

Agra, M.F., Silva, K.N., Basílio, I.J.L.D., França, P.F., Barbosa-Filho, J.M., 2008. Survey of medicinal plants used in the region Northeast of Brazil. Rev. Bras. Farmacogn. 18, 472-508. http://dx.doi.org/10.1590/S0102-695x2008000300023.

Brandão, H.N., David, J.P., Couto, R.D., Nascimento, J.A.P., David, J.M., 2010. Chemistry and pharmacology of antineoplasic chemoterapeutical derivatives from plants. Quim. Nova 33, 1359-1369. http://dx.doi.org/10.1590/S0100-40422010000600026.

Brandão, H.N., Medrado, H.H.S., David, J.P., David, J.M., Pastore, J.F.B., Meira, M., 2017. Determination of podophyllotoxin and related ariltetralin lignans by HPLC/ DAD/MS from Lamiaceae species. Microchem. J. 130, 179-184. http://dx.doi.org/ 10.1016/j.microc.2016.09.002.

Ferreira, D.F., 2011. Sisvar: a computer statistical analysis system. Ciência e Agrotecnologia 35, 1039-1042.

Harley, R.M., Pastore, J.F.B., 2012. A generic revision and new combinations in the Hyptidinae (Lamiaceae), based on molecular and morphological evidence. Phytotaxa 58, 1-55. http://dx.doi.org/10.11646/phytotaxa.58.1.1.

Hussain, M.S., Fareed, S., Ansari, S., Rahman, M.A., Ahmad, I.Z., Saeed, M., 2012. Current approaches toward production of secondary plant metabolites. J. Pharm. Bioall. Sci. 4, 10-20. http://dx.doi.org/10.4103/0975-7406.92725.

Medrado, H.H.S., David, J.M., David, J.P., Brandão, H.N., 2015. Distribution, biological activities, synthesis, and purification methods for podophyllotoxin and its derivatives. Quim. Nova 38, 243-258. http://dx.doi.org/10.5935/0100-4042.20140294.

Murashige, T., Skoog, F., 1962. A revised medium for rapid growth and bioassays with tobacco tissue cultures. Physiol. Plant 15, 473-479.
Novelo, M., Cruz, J.G., Hernandez, L., Pereda-Miranda, R., Chai, H.Y., Mar, W., et al., 1993. Cytotoxic constituents from Hyptis verticillata. J. Nat. Prod. 56, 1728-1736. http://dx.doi.org/10.1021/np50100a011.

Och, M., Och, A., Ciesla, L., Kubrak, T., Pecio, L., Stochmal, A., Kocki, J., Bogucka-Kocka, A., 2015. Study of cytotoxic activity, podophyllotoxin, and deoxypodophyllotoxin content in selected Juniperus species cultivated in Poland. Pharm. Biol. 53, 831-837. http://dx.doi.org/10.3109/13880209.2014.943246.

Raffauf, R.F., Kelley, C.J., Ahmad, Y., Le Quesne, P.W., 1987. $\alpha$-and $\beta$-Peltatin from Eriope macrostachya. J. Nat. Prod. 50, 772-773. http://dx.doi.org/10.1021/np50052a043.

Sagar, B.P.S., Zafar, R., 2005. In Vitro-Enhanced Production of podophyllotoxin in phytohormonal-induced and regenerated roots of Podophyllum hexandrum. Pharm. Biol. 43, 404-410. http://dx.doi.org/10.1080/13880200590963349.

Santos, E.O., Lima, L.S., David, J.M., Martins, L.C., Guedes, M.L.S., David, J.P., 2011. Podophyllotoxin and other aryltetralin lignans from Eriope latifolia and Eriope blanchetii. Nat. Prod. Res. 25, 1450-1453. http://dx.doi.org/10.1080/ 14786410902809500.

Suárez-Ortiz, G.A., Cerda-García-Rojas, C.M., Hernández-Rojas, A., Pereda-Miranda, R., 2013. Absolute configuration and conformational analysis of brevipolides, bioactive 5, 6-dihydro- $\alpha$-pyrones from Hyptis brevipes. J. Nat. Prod. 76, 72-78. http://dx.doi. org/10.1021/np300740h.

Suárez-Ortiz, G.A., Cerda-García-Rojas, C.M., Fragoso-Serrano, M., Pereda-Miranda, R., 2017. Absolute configuration and conformational analysis of brevipolides, bioactive 5, 6-dihydro- $\alpha$-pyrones from Hyptis brevipes. J. Nat. Prod. 80, 181-189. http://dx.doi. org/10.1021/acs.jnatprod.6b00953.

Vijayan, A., Pillai, P.P., Hemanthakumar, P., Krishnan, P., 2015. Improved in vitro propagation, genetic stability and analysis of corosolic acid synthesis in regenerants of Lagerstroemia speciosa (L.) Pers. by HPLC and gene expression profiles. Plant Cell Tissue Organ 120, 1209-1214. http://dx.doi.org/10.1007/s11240-014-0665-3. 